\title{
Workers, Warriors and Criminals: Social Conflict in General Equilibrium
}

\author{
Ernesto Dal Bó \\ U.C. Berkeley \\ Pedro Dal Bó* \\ Brown University
}

September 22, 2004

\begin{abstract}
We analyze how economy-wide forces (i.e.shocks to terms of trade, technology and endowments) affect the intensity of social conflict. We see conflict phenomena such as crime and civil war as involving resource appropriation activities. We show that not all shocks that could make society richer will reduce conflict. Positive shocks to labor intensive industries will diminish social conflict, while positive shocks to capital intensive industries will increase it. The key requirement is that appropriation activities be more labor intensive than the economy. Our model can explain the positive association between crime and inequality, and the curse of natural resources; it predicts that aid in kind to war-ridden societies will have perverse effects, and offers guidance on how to integrate international trade policy and peacekeeping efforts. Including appropriation activities into a canonic general equilibrium model introduces a social constraint to policy analysis. Thus, we can also account for populist policies, apparently inefficient redistribution and "national development strategies".
\end{abstract}

JEL Classification: D72, D74, D78, F13, H23, K42, O1.

Keywords: conflict, civil war, crime, social constraint, populism, trade policy, inefficient redistribution.

*We thank Rafael Di Tella, Herschel Grossman, Juan Carlos Hallak, Ben Hermalin, Daniel Heymann, Edward Miguel, and participants in various conferences and seminars. 


\section{Introduction}

One crucial aspect of social life is the conflict over the distribution of resources. The division of wealth among individuals is not solely determined by a price system operating on the basis of well defined and perfectly enforced property rights. In reality, expropriatory efforts play an important role, and take various forms. Sometimes an agent will engage in criminal activities-either acting alone or as part of a group-with the undisguised intention to expropriate goods from others. Some other times individuals may join a guerrilla that is motivated by ideology, but that in fact is (at least partly) fueled by the group's ability to appropriate resources.

Economics has historically analyzed phenomena like crime, on the one hand, and revolts and political instability, on the other, along separate lines. ${ }^{1}$ These phenomena, however, recognize a common root: they are symptoms of social conflict in the sense that they express individual and group pressures for the appropriation of resources. This paper offers a simple general equilibrium framework to study how economy-wide forces affect the extent of social conflict seen as an appropriation-based phenomenon. ${ }^{2}$

Both microfounded theoretical models and empirical evidence suggest that, all else equal, a lower opportunity cost in terms of wages in the labor market should increase the chance that an individual engages in activities such as rebellion or crime. ${ }^{3}$ This knowledge alone, however, is not sufficient to predict how aggregate economic shocks or policy interventions will affect the extent of social conflict. One key reason is that usually all else is not equal: real life shocks affecting the opportunity costs of conflict also tend to affect the returns to conflict and viceversa. Our model provides an integrated view of how the costs and benefits to conflict activities move in response to shocks (or policies). Thus, we can make predictions on how such shocks will affect phenomena like crime, and account for stylized facts of civil wars.

\footnotetext{
${ }^{1}$ Classic references in the literature on crime are Becker (1968) and Ehrlich (1973). Various references to work on revolts are given below.

${ }^{2}$ Whether the fight for resources takes the form of atomistic criminals or large, politically organized factions will depend on many factors shaping what we could call the industrial organization of social conflict. In this paper we choose to abstract from all issues regarding the number and size of competing groups, as well as from strategic interactions, to focus on what we deem to be more basic aspects, such as the determinants of the relevant costs and benefits to the expropriatory efforts.

${ }^{3}$ There is evidence that a higher income per capita is associated with a lower likelihood of civil conflict (Collier and Hoeffler, 1998, Elbadawi and Sambanis, 2002, Fearon and Laitin, 2003; Miguel, Satyanath and Sergenti, 2004), and MacCulloch (2001) finds that higher household income diminishes the propensity to express support for a revolt. Empirical studies on the relationship between wages and crime suggest that higher wages deter participation in criminal activities (see Grogger, 1998 and Gould, Weinberg and Mustard, 2002).
} 
In particular, our model shows that wealth-increasing shocks may both increase and decrease conflict. What really matters in our model is the relative factor intensity of the sectors in the economy that are initially affected. Our general equilibrium model of a small open economy comprises two productive sectors and a third sector we call "appropriation." This last sector expropriates a fraction of what is produced in the two productive industries. Assuming that appropriation is labor intensive relative to the whole economy, we show that an exogenous increase in the price of the capital intensive good will cause the appropriation sector to expand. (Conversely, a decrease in that price or an increase in the price of the labor intensive good will lead to a smaller appropriation sector.) The reason is that an increase in the price of the capital intensive good will expand the capital intensive industry, and contract the labor intensive one. This makes labor relatively less scarce, resulting in a lower cost of the appropriation activity relative to the amount of appropriable resources. Technological progress, which makes society richer, has similar effects: neutral technical progress in the labor intensive sector will decrease conflict but progress in the capital intensive sector will increase it. The effects of changes in endowments can also be analyzed: an increase in the capital endowment, for instance, will increase conflict. We also show that the social backlash of appropriation activities can be so strong that shocks that would make a conflictfree economy richer will leave everybody worse off.

The model is useful to explain empirical patterns in crime and civil wars. First, it can account for the positive association between crime and inequality. ${ }^{4}$ Capital and labor in our model can be interpreted to represent differently skilled labor forces. Any favorable shock to the skilled labor intensive sector will increase the wage gap across skill levels and will increase conflict whenever appropriation is relatively intensive in unskilled labor. Also, in our model these movements are compatible with an increase in total production. Thus, our model can explain why reforms that increase income per capita may be associated with increasing crime and inequality. An example is that of Argentina, where sweeping market-friendly reforms where introduced starting in $1991 .^{5}$

The model can also account for stylized facts of civil wars that appear paradoxical. On the one hand, there is the abovementioned evidence that a higher income per capita is associated with a lower likelihood of conflict. On the other hand, however, not all wealth-increasing forces appear to diminish conflict: Collier and Hoeffler (1998) report that a larger availability

\footnotetext{
${ }^{4}$ Fajnzylber, Lederman and Loayza (2002) document this connection across countries. There is also evidence that income inequality increases individual propensity to express support for a revolution (see MacCulloch, 2001).

${ }^{5}$ The following years saw important increases in income per capita, inequality and crime in the country. GDP per capita increased by $40 \%$ between 1991 and 1998. The Gini coefficient went from 44.7 to 49.5 between 1992 and 1998, and crimes against property increased by roughly 71\% between 1991 and 1998 .
} 
of natural resources can increase the risk and duration of civil war. Our model can explain these patterns. It predicts that a shock such as a drought-a negative shock to agricultural productivity and income-will fuel conflict in countries where agriculture uses relatively little capital, as in Subsaharan Africa (see Miguel et al, 2004). But our model also predicts that technical progress or new reserve discoveries in oil or diamonds will increase conflict when these extractive industries are relatively capital intensive, regardless of the fact that these shocks should also increase income.

Over the last few decades, the development of Political Economics has allowed us to incorporate political constraints into theory and policy analysis. In a similar spirit, our framework brings a social constraint to bear on the analysis of economic policy. We find that taxing capital and subsidizing productive labor can make both workers and capitalists better off: although capitalists lose when paying taxes they may gain more from less intense expropriation. When administering such tax-subsidy schemes is difficult (weak states may have trouble identifying who is really doing productive work), the promotion of unproductive public employment can be Pareto-improving. Thus, some forms of populism, including redistribution through wasteful channels, can be accounted for as rational responses to environments with social conflict. ${ }^{6}$ Similarly, policy interventions that shield the economy from certain shocks to terms of trade and technology may become desirable. Such interventions can include $(i)$ trade protection of labor intensive industries and $(i i)$ subsidizing technical progress in labor intensive industries while discouraging the adoption of foreign-based innovations that might be biased towards the capital intensive sector. These results may help rationalize the political support often enjoyed by policies that protect labor intensive industries. They also resonate with proposals by development theorists aligned with the Latin American structuralism (see for example Prebisch, 1959, on how national development strategies could use selective interventions).

The policy applications of the model reach the international efforts to stop violent conflict in the third world. One implication of our model is that aid in kind may have perverse effects, because it does not affect the returns to labor, but it increases the mass of lootable resources. Also, peace efforts may need to be coordinated with international trade agreements. Otherwise, the trade policies chosen by industrial powers may undermine their peace efforts abroad. To the best of our knowledge, our model provides the first framework with which to analyze the integration of trade and peace policies.

Our approach abstracts from several factors that may affect conflict. Examples are income effects, unemployment, and additional connections between natural resources and conflict. ${ }^{7}$

\footnotetext{
${ }^{6}$ See Coate and Morris (1995) and Acemoglu and Robinson (2001a) for different explanations of inefficient redistribution mechanisms.

${ }^{7}$ Extractive activities, for example, tend to be associated with monopolic rents. These in turn are as-
} 
Previous papers on conflict (see for instance Garfinkel, 1990; Grossman, 1991; Skaperdas, 1992; Hirshleifer, 1995; Grossman and Kim, 1995; Acemoglu and Robinson, 2001b; Powell, 2004) have studied a variety of problems we do not deal with. Examples are the determinants of military expenditures in repeated interactions among countries, the failure of cooperation in set ups where coercion is possible, and the determination of investment in production versus offensive and defensive capabilities.

Our model can be thought to have implications for rent-seeking. In particular, our appropriation sector could be thought to capture rent-seeking efforts under exogenous tariffs (on this topic, see for instance Krueger, 1974; and Bhagwati and Srinivasan, 1980). Besides differences in focus and modeling choices, our theory differs from Kruger's and Bhagwati and Srinivasan's in that our theory reserves a role for the relative use of factors across industries.

The plan for the paper is as follows. Section 2 presents the model. Section 3 characterizes the equilibrium after proving its existence. Then a comparison is made with the equilibrium in a conflict-free society. Section 4 studies how economic shocks affect the extent of social conflict, thus establishing our central results. Section 5 establishes further results and discusses policy implications. Section 6 extends the basic model to the case of industry-specific factors. Section 7 concludes.

\section{The model}

Consider an economy comprising two productive sectors along the lines of the canonical 2x2 international economics model. ${ }^{8}$ The productive sectors involve many firms which maximize profits and use technologies characterized by constant returns to scale. In a competitive equilibrium profits are driven to zero. The two productive sectors or industries are labeled 1 and 2, and they use two inputs, capital and labor, respectively labeled $K$ and $L$. All firms in each industry share the same production function with the property that industry 1 is more capital intensive than industry 2. We denote with $r$ and $w$ the respective rental prices of capital and labor. The given primitives of the model are: the factor endowments, available in fixed amounts $\bar{K}$ and $\bar{L}$; the technologies; and the prices of output, which are internationally determined and are labeled $p_{1}$ for industry 1 , and $p_{2}=1$ for industry 2 . (Good 2 is the numeraire.)

In addition to the productive sectors, there exists an appropriation sector. This sector

sociated with higher corruption, and the latter can be expected to damage the quality of institutions and economic performance. The end result may well be higher conflict. For the connection between rents and corruption see Ades and Di Tella (1999), and for the role of institutions see Acemoglu, Johnson and Robinson (2001). Ross (2003) lists various connections between natural resources and conflict.

${ }^{8}$ See Stolper and Samuelson (1941) and Jones (1965). 
only uses labor $\left(L_{A}\right)$ and produces a redistribution of output from the productive industries towards the appropriation sector. ${ }^{9}$ The technology of appropriation is summarized by the continuous and concave function $A\left(L_{A}\right)$, with $A(0) \geq 0$ and $A(\bar{L}) \leq 1$. The function $A\left(L_{A}\right)$ specifies the fraction of the total production value that is appropriated when $L_{A}$ units of labor are devoted to expropriatory activities. The concavity assumption reflects congestion effects in appropriation. Given production levels $q_{1}$ and $q_{2}$ in the two industries, and $L_{A}$ units of labor devoted to appropriation, the amount appropriated is $A\left(L_{A}\right)\left[p_{1} q_{1}+q_{2}\right]$. Given that under constant returns to scale payments to factors exhaust the value of production, the appropriated amount can be written as $A\left(L_{A}\right)\left[r \bar{K}+w\left(\bar{L}-L_{A}\right)\right]$. One can interpret that appropriation targets factor owners and steals a fraction of their returns. Also it can be interpreted that a fraction of their endowments is stolen. Alternatively, one can imagine that appropriation targets the output or revenues of firms. In any case, $r$ and $w$ represent the gross (before appropriation) rental prices of capital and labor in the productive sectors. We assume that the appropriated output is distributed uniformly among all labor involved in the appropriation sector. Given that there is free entry into the appropriation sector, the amount of labor in this sector is determined by the equality of the average appropriation and the opportunity cost to appropriation (the net wage).

An important clarification is due: our model abstracts from all loses that expropriatory activities may cause by way of destruction of life and property. Incorporating those is straightforward and would not affect our results.

\section{The equilibrium}

In this section we characterize conditions for existence of an equilibrium with appropriation in our economy. We then describe this equilibrium and compare it to that in an economy where social conflict is absent.

For most of the analysis it is useful to define the minimum unit-cost requirements of inputs in each industry: $a_{i j}$ is the amount of input $j$ used to produce one unit of output $i$ at minimum cost (given $r$ and $w$ ).

We focus on equilibria without productive specialization (i.e. both $q_{1}$ and $q_{2}$ are positive). ${ }^{10}$ Given the technology, output prices $\left(p_{1}\right)$ and factor endowments $(\bar{K}$ and $\bar{L})$, the

\footnotetext{
${ }^{9}$ The extreme assumption that the appropriation sector uses no capital is made for simplicity only. The necessary and sufficient condition for our results to emerge is that the appropriation sector be more labor intensive than the overall economy. This allows for appropriation being less labor intensive than the labor intensive industry. See the appendix for a demonstration.

${ }^{10}$ Our results involving changes in output prices and technical change go through even under specialization. The results on endowments, on the other hand, are specific to the no specialization cone.
} 
equilibrium of the model determines the rental price of factors ( $r$ and $w$ ), the output production levels $\left(q_{1}\right.$ and $\left.q_{2}\right)$, and the utilization of factors in each sector $\left(K_{1}, K_{2}, L_{1}, L_{2}\right.$ and $\left.L_{A}\right)$.

Three sets of conditions must be satisfied in a competitive equilibrium. First, firms in the productive industries must earn zero profits:

$$
\begin{aligned}
& r a_{1 K}+w a_{1 L}=p_{1} \\
& r a_{2 K}+w a_{2 L}=1 .
\end{aligned}
$$

Second, the market for factors must clear:

$$
\begin{aligned}
q_{1} a_{1 K}+q_{2} a_{2 K} & =\bar{K} \\
q_{1} a_{1 L}+q_{2} a_{2 L} & =\bar{L}-L_{A} .
\end{aligned}
$$

Third, a no arbitrage condition must hold, in the sense that labor must obtain similar returns when engaging in appropriation as when it is employed by the productive industries:

$$
\frac{A\left(L_{A}\right)}{L_{A}}\left[r \bar{K}+w\left(\bar{L}-L_{A}\right)\right]=\left[1-A\left(L_{A}\right)\right] w .
$$

This last condition merely says that the payoff from appropriation (the value of appropriated goods per unit of labor deployed to expropriation) must equal the returns from work net of appropriation losses. The former is captured by the left hand side in equation (5): the average productivity at appropriation is $\frac{A\left(L_{A}\right)}{L_{A}}\left[p_{1} q_{1}+q_{2}\right]$, which equals the left hand side in virtue of constant returns to scale in the productive industries. The opportunity cost to appropriation is the net return to productive labor, given by the right hand side. This expression is obvious in the case that appropriation targets factor owners, but also applies to any of the other interpretations given before. ${ }^{11}$

This formulation captures a competitive situation where labor owners can deploy their efforts in the appropriation sector, either individually, or in groups that share evenly the

\footnotetext{
${ }^{11}$ In the case when it is the output of firms that is targeted, the value of production available for repaying factors will be affected by the same coefficient. The reader might wonder whether the existence of appropriation should affect the first two equations in the system, which appear exactly as in the canonic model without appropriation. Firms would obtain net prices affected by a factor $1-A($.$) in the right hand side,$ and we would get some other equilibrium factor prices $\hat{w}, \hat{r}$. Now note that the unitary input requirement coefficients are homogeneous of degree zero in factor prices. Then, because the system (1)-(2) has a unique solution, we must have $\hat{w}=(1-A) w$ and $\hat{r}=(1-A) r$. All factors $1-A$ disappear, and we are left with the same first pair of equations.
} 
proceeds from appropriation. Similar results are obtained in the case where appropriation is not characterized by competition but rather by monopoly. ${ }^{12}$

\subsection{Existence}

Proposition 1 If there exists an equilibrium without specialization for the economy without appropriation and $A(\bar{L})$ is sufficiently small, then there is also an equilibrium without specialization for the economy with appropriation.

Proof. Note that $L_{A}$ does not appear in equations (1) and (2). Thus, the existence of an appropriation sector does not affect the gross rental price of factors unless it results in specialization. The condition for no specialization in an economy without appropriation is $\frac{a_{2 K}}{a_{2 L}}<\frac{\bar{K}}{\bar{L}}<\frac{a_{1 K}}{a_{1 L}}$, while that in the economy with appropriation is $\frac{a_{2 K}}{a_{2 L}}<\frac{\bar{K}}{\bar{L}-L_{A}}<\frac{a_{1 K}}{a_{1 L}}$. In other words, the amount of $L_{A}$ that solves equation (5) should be small enough (say $L_{A}$ is below some level we label $\widehat{L}$ ). Simplifying equation (5) we have that $A\left(L_{A}\right)=\frac{w}{r \bar{K}+w \bar{L}} L_{A}$. If $A(0)=0, L_{A}=0$ is an equilibrium, and whenever $A^{\prime}(0)>\frac{w}{r \bar{K}+w \bar{L}}$ there is also an equilibrium with posistive $L_{A}$ determined by the intersection of $A\left(L_{A}\right)$ with $\frac{w}{r \bar{K}+w \bar{L}} L_{A}$. If $A(0)>0$ equilibrium is unique and $L_{A}$ is positive. If $A(\bar{L})$ is sufficiently small the interior solution satisfies $L_{A}<\widehat{L}$, given that $A\left(L_{A}\right)$ is increasing, and the economy does not specialize.

In the remainder of the paper we focus on the interior solution for $L_{A}$.

\subsection{Comparison of economies with and without conflict}

The economies with and without an appropriation sector can be easily compared. In the case of no specialization that we focus on, the existence of an appropriation sector does not affect the absolute gross rental prices of factors. These are solely determined by the characteristics of productive technologies, and the amount of labor engaging in appropriation is residually determined in equations (3) to (5) so that the market for factors will clear and no one will gain by reallocating labor units across activities.

The presence of appropriation activities, however, does affect the rental prices net of appropriation that factor owners actually receive. In fact, the existence of an appropriation sector hurts all agents, including those who go into the appropriation sector.

\footnotetext{
${ }^{12}$ In this case we could think that the monopolic appropriation entrepreneur hires labor and must pay each unit the equivalent to the (net of appropriation) wage they can earn in the productive industries $\left[1-A\left(L_{A}\right)\right] w$. The revenues for the monopolist are $A\left(L_{A}\right)\left[r \bar{K}+w\left(\bar{L}-L_{A}\right)\right]$, so he will choose $L_{A}$ to maximize profits, yielding an analog to equation (5): $A^{\prime}\left(L_{A}\right)(r \bar{K}+w \bar{L})=w$. The resulting model yields identical comparative statics results to those we show in this paper.
} 
Proposition 2 The existence of the appropriation sector makes the owners of capital and labor worse off.

Proof. If there is no specialization, the rental price of factors are the values of $r$ and $w$ that solve equations (1) and (2). Then, total incomes to capital and labor without an appropriation sector are $r \bar{K}$ and $w \bar{L}$, respectively. With appropriation without specialization, the gross rental prices of factors do not change but the net rental prices are respectively $\left(1-A\left(L_{A}\right)\right) r$ and $\left(1-A\left(L_{A}\right)\right) w$. Therefore, total incomes to capital and labor with an appropriation sector are $\left(1-A\left(L_{A}\right)\right) r \bar{K}$ and $\left(1-A\left(L_{A}\right)\right) w \bar{L}$, respectively.

The possibility that workers may become criminals or warriors poses a paradox, in that they will end up worse off than if they could commit not to leave productive activities. In this sense, workers play a prisoner's dilemma when making their career decisions. ${ }^{13}$

In addition, appropriation affects the relative importance of the productive sectors in the economy.

Proposition 3 The existence of the appropriation sector increases the production of the capital intensive good and reduces the production of the labor intensive good.

Proof. If there is no specialization, the rental price of factors are the values of $r$ and $w$ that solve equations (1) and (2). These determine the values of $a_{1 K}, a_{2 K}, a_{1 L}$ and $a_{2 L}$ in equations (3) and (4). Given the amount of factors available for production $\left(\bar{K}\right.$ and $\left.\bar{L}-L_{A}\right)$ these equations determine the levels of production in the two productive industries. It can be easily shown that:

$$
\begin{aligned}
q_{1} & =\frac{a_{2 L} \bar{K}-a_{2 K}\left(\bar{L}-L_{A}\right)}{a_{1 K} a_{2 L}-a_{1 L} a_{2 K}} \\
q_{2} & =\frac{a_{1 K}\left(\bar{L}-L_{A}\right)-a_{1 L} \bar{K}}{a_{1 K} a_{2 L}-a_{1 L} a_{2 K}}
\end{aligned}
$$

so increments in $L_{A}$ must increase $q_{1}$ and reduce $q_{2}$ when $\frac{a_{2 K}}{a_{2 L}}<\frac{a_{1 K}}{a_{1 L}}$.

This proposition is an application of Rybczynski's (1955) theorem, and it tells us that the presence of conflict enlarges the capital intensive sector. This has implications for the empirical study of the connection between conflict and natural resources. In countries where extractive industries are relatively capital intensive, they could account for a larger share of economic activity as a consequence-and not a cause of conflict. As will be shown below, our

\footnotetext{
${ }^{13}$ Of course, with productive specialization, the existence of an appropriation sector would result in an increase in the wages paid by firms. If this increase is greater than the "appropriation tax", workers would be better-off with the existence of the appropriation sector.
} 
model also predicts a causality effect going in the opposite dicrection: shocks that enlarge extractive, capital intensive activities will increase conflict. This two-way causation poses a challenge to empirical work trying to estimate the impact of natural resource availability on conflict.

\section{Shocks and the intensity of social conflict}

We study now how changes in the parameters of the model affect the level of conflict. We first study changes in output prices.

\subsection{Changes in the terms of trade}

Changes in the price of commodities affect the rental price of factors. In an economy with an appropriation sector, this effect is the same as in an economy without an appropriation sector.

Lemma 1 (Stolper and Samuelson) An increase of the price of the capital intensive output results in an increase in the rental price of capital and a decrease in the rental price of labor $\left(\frac{d r}{d p_{1}}>0\right.$ and $\left.\frac{d w}{d p_{1}}<0\right)$.

Proof. Differentiating equations 1 and 2 and using the envelope theorem it is straightforward to show that:

$$
\begin{aligned}
& \frac{d r}{d p_{1}}=\frac{a_{2 L}}{a_{1 K} a_{2 L}-a_{1 L} a_{2 K}}>0 \\
& \frac{d w}{d p_{1}}=\frac{-a_{2 K}}{a_{1 K} a_{2 L}-a_{1 L} a_{2 K}}<0
\end{aligned} .
$$

This fundamental result of international economics is key to two of the central results of this paper, captured in propositions 4 and 5 .

Proposition 4 An increase in the price of the capital intensive output results in an increase in the activity level of the appropriation sector $\left(\frac{d L_{A}}{d p_{1}} \geq 0\right)$.

Proof. The equilibrium condition for the appropriation sector can be written as $A\left(L_{A}\right)=$ $\frac{1}{\frac{r}{w} \bar{K}+\bar{L}} L_{A}$. The conditions for the implicit function theorem are satisfied, so we can write $L_{A}$ as a function of $p_{1}$. Differentiating the previous equality with respect to $p_{1}$ we obtain: $\left.\frac{d L_{A}}{d p_{1}}=-\frac{\frac{\bar{K} L_{A}}{\left(\frac{r}{w} \bar{K}+\bar{L}\right)^{2}} \frac{d\left(\frac{r}{w}\right)}{d p_{1}}}{\left[A^{\prime}-\frac{r}{\frac{r}{w}} \bar{K}+\bar{L}\right.}\right]$.

The denominator is negative from the concavity of $A\left(L_{A}\right)$ and the equilibrium condition in the appropriation sector. Then, $\frac{d L_{A}}{d p_{1}}$ has the sign of $\frac{d\left(\frac{r}{w}\right)}{d p_{1}}$, which is positive by Lemma 1 (Stolper-Samuelson). 
The intuition for this result is as follows. The key idea is that the level of conflict in our model responds to a balance between the opportunity cost of expropriatory activities and the value of potentially expropriable resources (as captured in the right and left hand sides of equation (5), respectively). An increase in the price of the capital intensive good expands the capital intensive sector while the labor intensive sector contracts. The latter sector releases more labor per unit of capital than the former sector can absorb at the initial factor prices. This can be thought to make labor a relatively less scarce good, lowering wages. This lowers the opportunity cost of the appropriation activity compared with the size of potentially lootable resources, thus leading to more conflict. The way this result arises from the model can be easily explained by means of Figure 1. A little manipulation of equation (5) shows that the amount of labor in the appropriation sector is determined by the intersection of the concave function $A\left(L_{A}\right)$ with the linear function $\frac{1}{\frac{r}{W}+\bar{L}} L_{A}$. By Lemma 1 , an increase of $p_{1}$ results in an increase of $r$ and a decrease of $w$. This, in turn, leads to a decrease in the slope of the linear function, resulting in an increase in $L_{A}$.

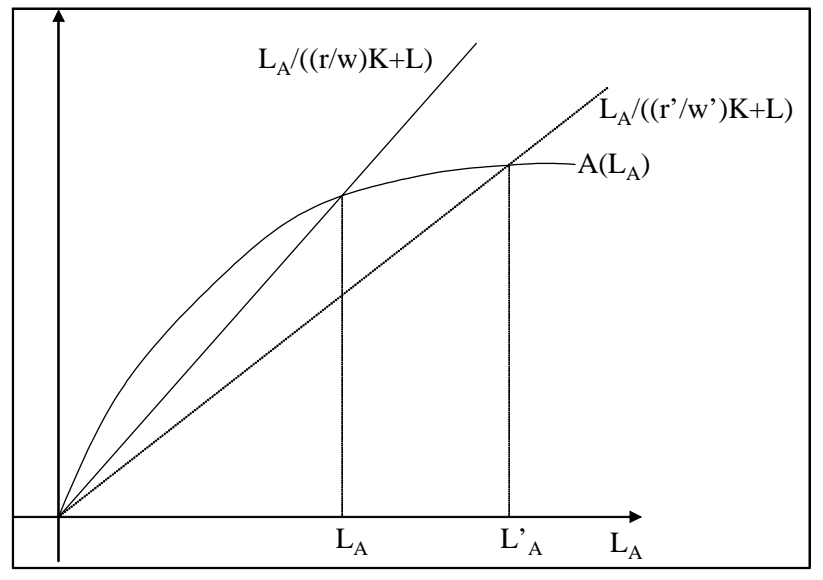

Figure 1: Prices and conflict

\subsection{Changes in Technology}

Technical progress unambiguously increases society's ability to create wealth. However, there are instances in which technical change will increase conflict.

Proposition 5 Neutral technical progress in the capital intensive sector results in an increase in social conflict.

Proof. Consider a neutral technical innovation that makes the capital intensive sector $1+\theta$ times more productive $(\theta>0)$. This implies that the zero profit condition in that 
sector can now be written as: $r a_{1 K}+w a_{1 L}=(1+\theta) p_{1}$. Therefore, technological progress in the capital intensive sector has the same effect on $r$ and $w$ as an increase of the price of the capital intensive good. The proposition then follows from Proposition 4.

Analogously, neutral technical progress in the labor intensive sector results in a decrease in social conflict. Note that the result that technical change will increase conflict does not rely on such change being of a labor-saving kind, which would of course yield the result more easily. Innovations can lead to more conflict even when being neutral.

\subsection{Changes in factor endowments}

Another source of variation in conflict levels may arise from changes in the amount of available factors. In particular, we might be interested in how a higher capital endowment will affect conflict.

Proposition 6 An increase in the amount of capital results in an increase in conflict $\left(\frac{d L_{A}}{d \bar{K}} \geq 0\right)$.

Proof. Differentiating the equilibrium condition for the appropriation sector with respect to $\bar{K}$ we obtain: $\frac{d L_{A}}{d \bar{K}}=-\frac{\frac{L_{A}}{\left(\frac{r}{W}+\overline{T^{2}}\right.}{ }^{\prime} \frac{r}{w}}{\frac{r}{w} \bar{K}+\bar{L}}$. The denominator is negative from the concavity of $A\left(L_{A}\right)$ and the equilibrium condition in the appropriation sector. Then, $\frac{d L_{A}}{d \bar{K}}>0$.

The explanation for this proposition is thus. Because in the no specialization case factor prices are only affected by technology, a higher availability of capital will not affect the opportunity cost to the appropriation sector. However, an economy with more capital produces more, so the amount of lootable resources increases, making appropriation more profitable. This results in an increase in the level of conflict. An analogous result can be obtained when considering the role of foreign aid to a society with high levels of conflict. Aid in kind does not affect the returns to productive labor, but, just like an increase in capital, it enlarges the amount of lootable resources. This, in turn, provides incentives for appropriation to increase.

Studying the effect of changes in the total endowment of labor requires that we redefine the appropriation technology so as to consider both the amount of labor in the sector and in the rest of the economy. When performing changes in the labor endowment, it seems more reasonable to postulate that appropriation is a function of the share of the overall labor force-rather than the absolute number of people-that are devoted to such activity (we can consider our previous formulation as including a normalization). Otherwise, as the population of a country grows, the appropriation sector would grow as well up to the point in which it takes over the whole economy. We then define appropriation as a function of the share of labor in the appropriation technology, i.e. $A\left(l_{A}\right)$ where $l_{A}=\frac{L_{A}}{\bar{L}}$. 
Proposition 7 An increase in the amount of labor results in an decrease in conflict $\left(\frac{d l_{A}}{d \bar{L}}<0\right)$.

Proof. The equilibrium condition for the appropriation sector can be written as $A\left(l_{A}\right)=$ $\frac{\bar{L}}{\frac{r}{w} \bar{K}+\bar{L}} l_{A}$. Differentiating this condition with respect to $\bar{L}$ we obtain: $\frac{d l_{A}}{d \bar{L}}=\frac{\frac{1}{\left(\frac{r}{w}+\bar{L}\right)^{\frac{r}{K}}} l_{A}}{A^{\prime}-\frac{\bar{L}}{w} \frac{\bar{L}}{\bar{K}+\bar{L}}}$. The denominator is negative from the concavity of $A\left(l_{A}\right)$ and the equilibrium condition in the appropriation sector. Then, $\frac{d l_{A}}{d \bar{L}}<0$.

The explanation of the previous proposition stated that, given $w$ and $r$, more capital leads to more lootable resources and hence to more appropriation. It would seem that this logic should extend to the case of labor as well, explored in the last proposition. However, when $\bar{L}$ increases the product does not increase as much (capital is being held fixed), so the appropriable resources per person go down. This causes the level of conflict to go down.

\section{Further results and applications}

In this section we study how the existence of conflict introduces a social constraint to policy analysis. We first examine how subsidies to workers in the productive sectors, financed with taxes to capitalists, can reduce the level of social conflict and enlarge the total value of production in the economy. We then explore the use of unproductive public employment to attain the same objective. We analyze next the policy implications of our proposition that technical progress in the capital intensive industry will increase conflict. We show that this increase in conflict can be as large as to make everybody worse off, so certain policies affecting the adoption of technical innovations might be justified. Finally, we examine a rationale for trade policy intervention, both from a domestic and an international perspective. The results of this section help explain how certain policy reforms that appear Pareto-improving in a frictionless model may be rendered inefficient by the social backlash to policy in a conflictive world. Once the social constraint is incorporated to policy analysis, policies that seem distortionary may instead be Pareto-improving. This is of course but an instance of the theorem of the second best: in the presence of a distortion, another distortion may improve matters. In our model, the distortion is given by the presence of expropriatory activities. The policies rationalized in this section-taxing capital to subsidize labor, promoting public employment, protecting labor intensive industries, intervening in the process of technology adoption-fit the populist stereotype. The results in this section suggest that such policies could emerge as a rational response under conflict, rather than as the result of clientelism, corruption, or a sheer taste for redistribution. 


\subsection{Taxes and social conflict}

Consider a tax-subsidy scheme such that workers in the productive sectors receive a subsidy equal to a fraction $s$ of the wage firms pay to them. To fund these subsidies, capitalists pay a tax equal to a proportion $t$ of the rent to capital. Given taxes $t$ and subsidies $s$, the equilibrium condition for the appropriation sector becomes:

$$
A\left(L_{A}\right)\left[r \bar{K}+w\left(\bar{L}-L_{A}\right)\right]=\left(1-A\left(L_{A}\right)\right)(1+s) w L_{A} .
$$

In addition we ask that the government keep a balanced budget:

$$
s w\left(\bar{L}-L_{A}\right)=\operatorname{tr} \bar{K} .
$$

The model is completed with equations (1) to (4).

Proposition 8 Giving a subsidy to productive labor reduces the level of conflict $\left.\left(\frac{d L_{A}}{d s}\right\rfloor_{s=0}<0\right)$.

Proof. The equilibrium condition for the appropriation sector can be written as $A\left(L_{A}\right)=$ $\frac{w L_{A}+\left(1-A\left(L_{A}\right)\right) s w L_{A}}{r \bar{K}+w \bar{L}}$. Differentiating this condition with respect to $s$, and evaluating the expression at $s=0$, we obtain: $\frac{d L_{A}}{d s}(s=0)=\frac{\left(1-A\left(L_{A}\right)\right) w L_{A}}{A^{\prime}\left(L_{A}\right)(r \bar{K}+w \bar{L})-w}$. The denominator is negative from the concavity of $A\left(L_{A}\right)$ and the equilibrium condition in the appropriation sector without subsidies. Then, $\frac{d L_{A}}{d s}(s=0)<0$.

The intuition for this result is direct. Subsidizing productive labor increases the opportunity costs of engaging in appropriation, thus reducing the latter. A subsidy to productive labor results in a shift of labor away from appropriation activities and towards the productive sectors of the economy. Therefore, the tax-subsidy scheme has a positive effect on the total amount of output in an economy with an appropriation sector. This provides an efficiency rationale for a set of policies that are usually considered solely redistributive: subsidies to productive labor increase the total size of the economy's "pie." If lump sum taxes and transfers were possible, then our tax-subsidy scheme would be Pareto optimal, because the total value of production could be increased while making sure capitalists are being left at least as happy as before paying any taxes. When dealing with the issue of social conflict, however, it may not be appropriate to assume that all transfers among agents are possible. For example, it might be impossible to tax the agents in the appropriation sector.

If we restrict ourselves to the case in which the government can only tax and subsidize agents in the productive sectors, the issue of the Pareto optimality of subsidies to productive labor becomes more complicated. We must study the effects of this policy in the net wages and rental price of capital. It is straightforward to see that a subsidy to productive labor always makes workers in the productive industries better off. The subsidy has two effects, 
1) it has a direct positive effect in the gross total wage, and, 2) it reduces the appropriation sector and hence the expropriation suffered by workers. Both effects go in the same direction, increasing the net income of workers. Those in the appropriation sector must also be better off given that in equilibrium they are indifferent regarding their career decisions. In the case of owners of capital, the two effects go in opposite directions: under the tax-subsidy scheme, 1) they pay a tax, but 2) the "appropriation tax" diminishes. If the second effect overcomes the first, we have that the proposed scheme makes both workers and capitalists better off. We now show by example that there are economies where the tax-subsidy scheme proposed above is Pareto-improving.

Example 1 Taxes, subsidies and social conflict in a Cobb-Douglas economy:

Consider an economy with production functions $q_{1}=K_{1}^{\frac{2}{3}} L_{1}^{\frac{1}{3}}$ for the capital intensive sector, and $q_{2}=K_{2}^{\frac{1}{3}} L_{2}^{\frac{2}{3}}$ for the labor intensive sector. Let us set the total endowments of the two factors of production at levels $\bar{K}=\bar{L}=100$. In this example we characterize the equilibrium both for the case without an appropriation sector $\left(L_{A}=0\right)$ and the case in which there is an appropriation sector with the following technology: $A\left(L_{A}\right)=\frac{L_{A}}{150+L_{A}}$. In the latter case we consider both the situation with no intervention $(s=t=0)$ and a situation with state intervention through a tax-subsidy scheme. In this case, we consider a subsidy to productive labor of $10 \%$ ( $s=0.1$ ), which is funded through a tax on capital. The public budget is balanced in equilibrium.

Figure 2 shows the output combinations that can be obtained in equilibrium for the different cases. The graph coincides with the production possibility frontier for the economy

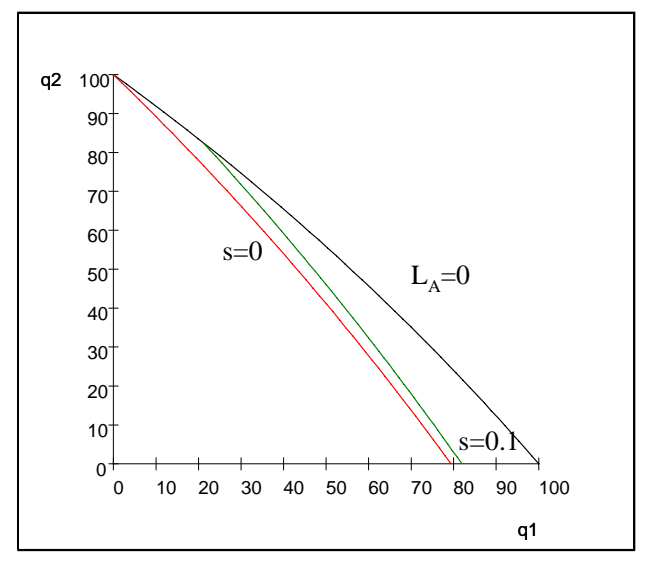

Figure 2: Equilibrium output pairs

without an appropriation sector (given the Pareto optimality of equilibria). That is not the case under social conflict, where the set of production pairs that can be obtained is to the 
south-west of the pairs for the economy without social conflict. The existence of social conflict introduces a wedge between what it is technically feasible and what can be obtained in equilibrium. Interestingly, a subsidy to productive labor moves the set of production pairs under conflict toward the ones without conflict. In fact, the subsidy allows for the total elimination of conflict in some cases, making both graphs coincide in the left upper part of the figure (when $p_{1}$ is relatively small).

While subsidies to productive labor make all workers better off, that is not necessarily the case with owners of capital. Figure 3 shows the net income of capital (net of government taxes and appropriation losses, labeled with "NIK") as a function of $p_{1}$ for the three different scenarios $\left(L_{A}=0, s=0, s=0.1\right)$. The figure shows that social conflict results in a lower income for capitalists. For relatively high levels of $p_{1}$, and given the existence of the appropriation sector, capitalists are better off with a subsidy to productive labor (and a tax to capital) than without it.

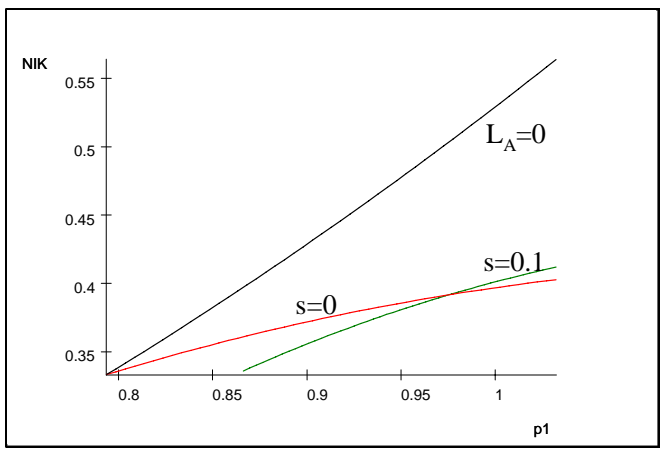

Figure 3: Net income of capital

\section{$5.2 \quad$ Unproductive public employment}

The tax-subsidy scheme introduced in the last subsection could be vulnerable to fraud. For example, an individual could appear in the firm's payroll and split the subsidy with the firm, while the individual is in fact comitting crimes rather than working. When the state is weak to stop such fraud, the scheme proposed above may be ineffective. An alternative for reducing conflict can be public employment. To the extent that it prevents individuals from devoting time to conflict activities, public employement (even when unproductive per se) can be a way to reduce the appropriation sector.

Suppose the state announces the employment of a fix number of public employees $L_{P}$, who will earn a wage $w_{P}>w$. Those that are not employed by the state must then decide between work and conflict. The state wage payments $w_{P} L_{P}$ must be funded with a tax on 
capital rents at rate $t$. The modified model now contains equations (1) to (4), where (4) now reads $q_{1} a_{1 L}+q_{2} a_{2 L}=\bar{L}-L_{A}-L_{P}$, and two more conditions. One is the equilibrium condition for the appropriation sector, which now is,

$$
A\left(L_{A}\right)\left[r \bar{K}+w\left(\bar{L}-L_{A}-L_{P}\right)\right]=\left(1-A\left(L_{A}\right)\right) w L_{A}
$$

and the other one is the government's balanced budget condition.

$$
w_{P} L_{P}=\operatorname{tr} \bar{K}
$$

We can now state,

Proposition 9 Promoting unproductive public employment reduces conflict $\left(\frac{d L_{A}}{d L_{P}}<0\right)$.

Proof. Factor prices are determined by equations (1) and (2) so they are the same as in the basic model. Rearranging equation (8) we get $A\left(L_{A}\right)=\frac{L_{A}}{\frac{r}{w}+\bar{L}-L_{P}}$. Differentiating this condition with respect to $L_{P}$ we obtain: $\frac{d L_{A}}{d L_{P}}=\frac{\frac{L_{A}}{\left(\frac{r}{w} \bar{K}-L_{P}\right)^{2}}}{A^{\prime}-\frac{1}{w} \bar{K}+\bar{L}-L_{P}}=0$, where the inequality follows from the denominator being negative. This follows from (8) and the concavity of $A($.$) .$

The proof just given corresponds to the no specialization case, where the main effect of public employment is reducing the amount of wealth that can potentially be disputed. The proposition, however, is also true for the specialization cases, where public employment also causes an increase in wages. This raises the opportunity costs of conflict, reducing appropriation even further. The extension just analyzed assumes that public employment is totally unproductive. Our result suggests that clientelistic practices that transfer income to target groups through public employment may have a favorable byproduct.

It can be shown by example that the reduction in conflict brought along by public employment can more than compensate its costs in terms of forgone production. Hence, the promotion of unproductive employment can be Pareto-improving. The economics literature has investigated the rationale for inefficient transfers to special interests. Coate and Morris (1995) offer an explanation on the basis of asymmetric information about two elements: the usefulness of policies and the motivations of politicians. Acemoglu and Robinson (2001a) offer an explanation based upon the possibility that inefficient mechanisms may enlarge the target group and consolidate its power. This subsection yields an alternative explanation. When the targetting of subsidies to productive labor is difficult, the promotion of unproductive labor can be attractive to society as a way to diminish conflict. 


\subsection{First world technological progress and third world conflict}

One would think that developing nations will be helped by technology transfers from rich nations: better technologies expand the production possibility frontier and make a country unambiguously richer. However, if developed nations are more capital intensive than developing ones, the innovations the former make available to the latter might be biased towards the capital intensive industry. The problem with the adoption of such innovations is that, as shown in Section 4, neutral technical progress in the capital intensive industry will increase conflict. Moreover, the increase in conflict can overcome the direct effect of technical progress on the production possibilities of the economy, resulting in a decrease in total production. As shown in the example below, the decrease in production can be so significant that even capitalists are worse off by the adoption of a technological innovation in the capital intensive sector. Firms in the capital intensive sector have incentives to adopt a better technology and make profits. In equilibrium, all firms in the sector adopt the improved technology and make zero profits. The impact on factor prices increases conflict, and this increase can be as strong as to leave all owners of labor and capital worse off.

Example 2 Technological progress and conflict:

Consider an economy with production functions $q_{1}=K_{1}^{\frac{2}{3}} L_{1}^{\frac{1}{3}}$ for the capital intensive sector, $q_{2}=K_{2}^{\frac{1}{3}} L_{2}^{\frac{2}{3}}$ for the labor intensive sector, and the following appropriation technology: $A\left(L_{A}\right)=\frac{3}{260}+\frac{1}{260} L_{A}$. Let us set the total endowments of the two factors of production at levels $\bar{K}=\bar{L}=100$ and let $p_{1}=1$. Figure 4 shows the total value of production in the economy for different levels of technological progress $(\theta)$ in the capital intensive sector. While an increase of $5 \%$ in the productivity of sector 1 results in an increase of total production, further increases actually have a negative effect on the total production of the economy.

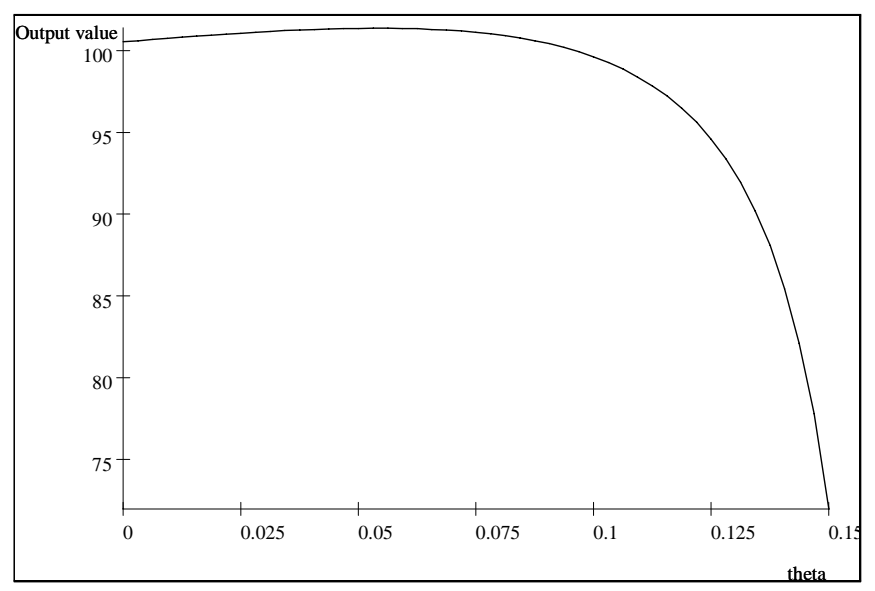

Figure 4: Technological progress and total production 
Figure 5 (below) shows the net incomes of capital and labor (labeled NIK and NIL respectively). Technical progress in the capital intensive sector hurts labor. There are two reasons for this: first, technical progress in the capital intensive sector reduces the gross wage paid by firms; second, there is an increase in the appropriation losses brought by the increase in conflict. The two forces work in different directions for capitalists. While technical progress in the capital intensive sector results in an increase in the gross rental price of capital, it also results in an increase in the appropriation they suffer. Figure 5 shows that the second effect overcomes the first one for relatively high rates of technical progress. As a result, both workers and capitalists are made worse off by technical progress.

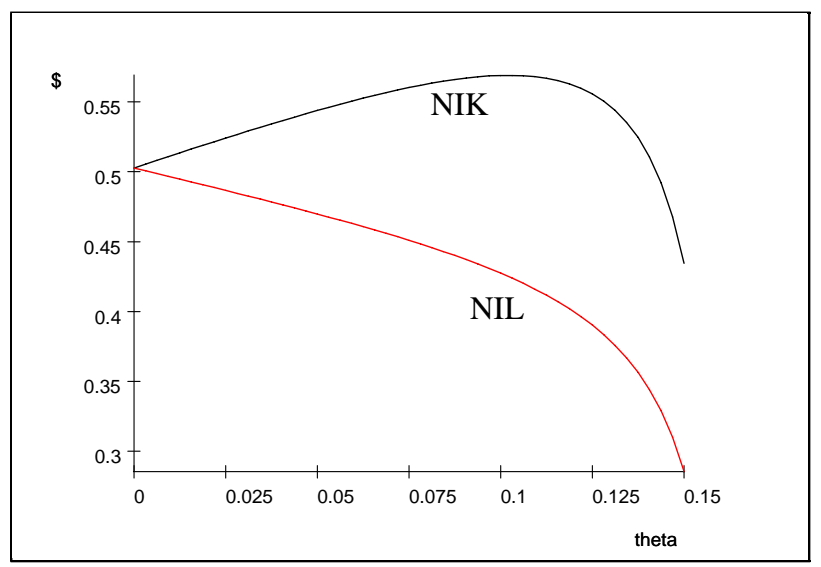

Figure 5: Technical progress and payments to factors.

The example suggests that developing nations with serious conflict issues may not want to adopt every technological improvement that richer countries make available to them, even if these come as a gift. In addition, a conflict-prone society may want to discourage innovation in the capital intensive sector, while encouraging it in the labor intensive sector. This course of action and the trade policies analyzed in the following subsection mirror the interventions proposed by Latin American structuralists (see for instance Prebisch, 1959) and other advocates of state-guided "national development strategies".

\subsection{Trade policy intervention and social conflict}

Domestic trade policy in the small economy

Here we explain how trade policy intervention in the small open economy can reduce social conflict, and how this intervention can be Pareto-improving. Imagine a country that 
is a net importer of goods produced in its labor intensive industry, and is a net exporter of goods produced in its capital intensive industry. Our Proposition 4 indicates that social conflict can be diminished through a raise in the price of the labor intensive good and a decrease in the price of the capital intensive good. Therefore, if the government desires to attain a reduction in conflict, it might consider imposing a tariff on imports. This protection will increase the price that domestic producers in the labor intensive sector can obtain for their goods, causing the expansion of the sector, an increase in wages, and a drop in social conflict. A reduction in social conflict can also be attained by taxing the exports of the capital intensive sector. In the converse case that the country is a net exporter of labor intensive goods, and a net importer of capital intensive goods, a government that wishes to diminish conflict would impose subsidies on both the labor intensive exports and the capital intensive imports.

In the previous subsection we showed that an improvement in the technology of the capital intensive industry can trigger an expansion of appropriation that is so high that everybody would be better off if the government found means to prevent the adoption of the improved technology. Note also that in our model the effect of neutral technical change is formally equivalent to a change in output price. This means that if a trade policy can affect the prices perceived by producers, then there must be trade interventions that make everybody better off. For concreteness, think of a trade intervention that lowers the producer price of the capital intensive good (a tax if the country is a net exporter of it, and a subsidy if it is a net importer). This intervention has the opposite effect to neutral technical progress in the capital intensive industry. Therefore, such trade policy will raise welfare whenever technical progress in the capital intensive industry leaves everybody worse off.

\section{International trade policy and social conflict}

In recent years the world has seen significant international policy efforts at preventing, controlling, and ending armed conflict. The peace keeping branch of the UN, for example, carries initiatives in a large number of countries. Some of these-notably some countries in Africa-have been involved both in interstate and civil conflicts where appropriation is widely known to play an important role. ${ }^{14}$ These peace keeping efforts face a significant obstacle in that the options to looting may not abound, thus making the decision to join

\footnotetext{
${ }^{14}$ The pervasive presence of appropriation of goods and even human beings in the context of Africa's civil wars is well documented. Mentions to looting and banditry in official documents are ubiquitous. An example is provided by the UN Secretary-General's report S/1997/80, on 26 January 1997 (available at <http://www.un.org/Depts/dpko/unamsil/UnamsilR.htm>). Therein the Secretary-General stated how thousands of village hunters were being recruited to defend villages "against looting from both the RUF and undisciplined RSLMF elements." (RUF means Revolutionary United Front and RSLMF means Republic of Sierra Leone Military Forces.)
} 
a guerrilla or to abuse a position of military authority more attractive. In the words of the UN Secretary-General regarding Sierra Leone, "As economic opportunities in the formal sector decline, people have little choice but to participate more fully in the informal economy, including resorting to acts of banditry. " 15 In this connection, economic development is seen as a potentially powerful antidote to conflict.

On the other hand, both Western democracies by themselves and the global community as represented by the UN pursue development efforts in the Third World, which include a traderelated dimension. Organizations such as the UN's Conference on Trade and Development (UNCTAD) and the United Kingdom's Direction for International Development (DFID) are spearheads to various initiatives that seek to help developing countries increase their exports to richer nations. However, the policies discussed in the context of trade and development strategies are never linked to the initiatives that the same set of actors pursue regarding peace keeping. Our model suggests that they should be connected, and how.

To see this, suppose we view access to first world markets for, say, processed agricultural products, as an improvement in the price for processed agricultural goods produced in a Subsaharan economy. Now suppose those goods are relatively labor intensive in the latter economies. Then our model predicts that better access to European markets for those goods would cause the labor intensive sector in Subsaharan economies to expand. This would make labor relatively scarcer in the latter economies, raising wages and diminishing conflict in Subsaharan Africa. Unfortunately, less developed countries face significant barriers to the markets in developed countries. Moreover, these tariffs are biased against less technology intensive exports (see Meller, 2003).

It follows from our model that when the possibility of lower protection to first world agriculture is discussed within the World Trade Organization, its benefits in terms of lower conflict in Africa might have to be taken into account. At the same time, higher European tariffs, subsidies and sanitary barriers to agricultural products may entail costs in terms of more painstaking peace efforts. Our model also warns that export oriented strategies as pursued by UNCTAD and DFID might have to focus on the fact that not every incomeenhancing change may reduce conflict. Fostering the expansion of labor intensive industries could constitute a pacifying force. But the expansion of extractive, more capital intensive activities (that happen to attract significant Western involvement), on the contrary, may instead fuel conflict. See our discussion on "conflict diamonds" in the next section.

\footnotetext{
${ }^{15}$ See report S/1995/975, 21 November 1995, by the UN Secretary-General in http://www.un.org/Depts/dpko/unamsil/UnamsilR.htm.
} 


\section{Conflict and factor specificity}

One might think that the predictions of our model are unrealistic in the short run, when some factors of production are fixed. For example, one might expect the Stolper-Samuelson theorem to fail: a positive shock to the price of oil could generate an increase in wages-rather than a decrease-even when oil extraction is a relatively capital intensive sector. But if more valuable natural resources will raise wages, can we still account for the curse of natural resources, whereby the availability of more valuable natural resources increases conflict? If anything, it would seem that such phenomenon must be explained with a model that is compatible with delivering higher conflict and higher wages when, say, the price of a natural resource goes up. In this section we attain precisely this explanation. We study the well known Ricardo-Viner model with industry-specific factors and add the appropriation sector. Therefore, the model is as in section 3, with the difference that while labor is still mobile across sectors, capital is not. There are two kinds of capital $\left(K_{1}\right.$ and $\left.K_{2}\right)$ which are specific to each productive industry. The respective endowments of capital are denoted with $\bar{K}_{1}$ and $\bar{K}_{2}$. The model with industry specific factors can be thought to capture short run movements (when capital is fixed), while our basic model in section 3 can be thought to capture long run effects (when all factors are mobile).

The Ricardo-Viner model has the property that any positive shock to a price increases wages. We show that natural resource shocks that raise wages are indeed compatible with higher, rather than lower, levels of conflict. The key aspect is that when extractive activities are relatively capital intensive, a shock to the price of natural resources will expand the returns to appropriation even more than it increases its opportunity costs.

Note that when there are industry specific factors of production, the definition of a sector as "labor intensive" is not too meaningful if one sticks with the definition used before, in terms of unit input requirement ratios. In the modified setup, we follow convention by saying an industry is relatively labor intensive when the participation of labor in that industry's income is relatively high. As is standard in the literature, let $\sigma_{i}$ denote the elasticity of substitution between labor and capital in sector $i$ (a negative number), and $\theta_{L_{i}} \equiv \frac{w L_{i}}{w L_{i}+r K_{i}}$ is the distributive share of labor in the income of sector $i$. We can now state,

Proposition 10 An increase in $p_{1}$ results in an increase in conflict $\left(\frac{d L_{A}}{d p_{1}} \geq 0\right)$ if and only if $\frac{\sigma_{1} \theta_{L 1}}{1-\theta_{L 1}} \geq \frac{\sigma_{2} \theta_{L 2}}{1-\theta_{L 2}}$. When elasticities of substitution are the same across industries (i.e. $\left.\sigma_{1}=\sigma_{2}\right)$, then an increase in $p_{1}$ results in an increase in conflict if and only if industry 1 is relatively capital intensive (i.e. $\theta_{L 1}<\theta_{L 2}$ ).

Proof: See Appendix. 
This proposition provides a clear condition under which a change in international prices would result in an increase in conflict. For example, if the elasticities of substitution are the same in both productive sectors, an increase in $p_{1}$ results in an increase in conflict if, and only if, sector one is relatively capital intensive. In addition, if the payments to labor are equal in both sectors, an increase in $p_{1}$ results in an increase in conflict if, and only if, sector one has, in absolute value, a lower elasticity of substitution than sector 2 . The reason is that the lower (in absolute value) the elasticity of substitution of sector 1 , the lower the positive impact of the increase of prices on wages.

This result holds regardless of the fact that an increase in $p_{1}$ will result in an increase in wages. The increase in $p_{1}$ results in an increase in the income of capital (the net effect of an increase in sector 1 and a decrease in sector 2) that is larger than the increase in wages. This makes the potential disputable wealth to rise more than wages, in turn making appropriation activities more attractive to workers. The model with specific factors makes clear that the main conclusions of this paper do not depend on the sign of the impact of shocks on wages. Instead, the results depend on the relative impact that shocks have on the retribution to capital and wages, as this governs the relative movements of the benefits and costs of conflict.

The previous proposition provides an explanation for the curse of natural resources. If sector 1 produces diamonds, an increase on the price of diamonds will result in an increase in conflict if this sector is highly capital intensive or displays a low elasticity of substitution between labor and capital compared to the rest of the economy.

But is it also the case that an increase in the specific endowment of the diamond industry (i.e. rough diamonds) would result in an increase in conflict? While in this model it is difficult to characterize in general the effects of endowment changes on the level of conflict, we provide such results for a Cobb-Douglas economy.

Proposition 11 In a Cobb-Doublas economy, an increase in the endowment of capital of the capital (labor) intensive sector results in an increase (decrease) of conflict.

\section{Proof: See Appendix.}

If we see natural resources such as oil or diamonds as specific capital to extractive activities, this section gives an explanation for the curse of natural resources. More resources increase conflict when extraction is a relatively capital intensive activity. Also, the model can be used to analyze the issue of "conflict diamonds". These are rough diamonds that are seen to fuel conflict because rebel factions have direct access to them and use the revenues to finance themselves (see Ross, 2003). As a result, governments and parties concerned with the diamond trade have engineered a certification process within an initiative known as the 
Kimberley process. ${ }^{16}$ The aim is to stamp out "conflict diamonds" and keep them away from the diamond market. The disturbing implication of our model is that every diamond may be a "conflict diamond": perfectly legal diamonds that have not been handled by rebels may also increase conflict.

\section{Conclusion}

We consider an economic activity we call "appropriation" in the context of the canonic 2x2 general equilibrium model of a small open economy. That activity only redistributes existing resources towards those engaging in it, and away from the productive industries. We see appropriation as a basic component of different manifestations of social conflict, such as crime or civil war. We prove existence of an equilibrium for the conflict-enhanced economy, and characterize it. Relative to the conflict-free benchmark, a conflictive society is more capital intensive, and both workers and capitalists are worse off. The possibility that workers may become warriors or criminals hurts everybody.

Our main results involve the comparative statics of that equilibrium. Not all shocks that tend to make society richer will diminish conflict. Rather, favorable shocks to the prices and the technology of the capital intensive sector will increase conflict. What appears to be a wealth-enhancing shock will only diminish conflict when favoring the relatively labor intensive industry. (The key condition for these results is that the appropriation activity be more labor intensive than the overall economy-i.e. appropriation could be less labor intensive than the relatively labor intensive industry.) Our model can then account for apparently paradoxical sylized facts concerning civil wars. It has been noted that both unfavorable circumstances (such as droughts) and favorable ones (such as higher availability of natural resources) increase the likelihood of conflict. The first piece of evidence can be explained as the result of negative shocks affecting a labor intensive sector, while the second can be explained as the result of positive shocks affecting relatively capital intensive activities.

A central theme in our paper is that shocks, affecting factor prices, alter both the costs and benefits to conflict. In particular, aggregate shocks affect both wages and disputable wealth. This is important to our predictions of how these shocks will affect conflict. For example, when capital is industry-specific, a positive shock to the capital intensive industry increases wages but it also increases disputable wealth, resulting in higher, rather than lower, conflict. Thus, although it is known that, all else equal, higher wages will diminish crime, certain shocks that raise wages may also increase crime, because not all else is equal.

We show the social backlash of increased conflict can be so strong as to leave society

\footnotetext{
${ }^{16}$ See <http://www.kimberleyprocess.com $>$.
} 
worse off after the realization of a shock that would make a conflict-free society richer. The distortion introduced by the possibility of appropriation activities renders attractive some policies that would be inefficient in a world where property rights can be perfectly enforced. Examples are "populist" interventions that tax capital and subsidize labor or that promote unproductive public employment, forms of trade intervention that go against the free trade credo, or "national development strategies" that distort the profile of technical innovations that are adopted by the country's industry.

Societies often implement policies that economists consider inefficient. Work on the political economy of endogenous policies (see, inter alia, Stigler, 1971, Peltzman, 1976, Becker, 1983 and Coate and Morris, 1995) has shown that such policies may be shaped by political constraints, and thus may be "politically efficient". An analogous case can be made when a social constraint is incorporated to economic analysis: policies that make no sense in a socially frictionless world may become attractive to society (and its politicians) in the face of social conflict.

\section{Appendix}

Proof of Proposition 10. The equilibrium conditions of the model now are:

$$
\begin{aligned}
L_{1}^{d}\left(\frac{w}{p_{1}}, \bar{K}_{1}\right)+L_{2}^{d}\left(w, \bar{K}_{2}\right)+L_{A} & =\bar{L} \\
\frac{A\left(L_{A}\right)}{L_{A}}\left[p_{1} f_{1}\left(L_{1}^{d}\left(\frac{w}{p_{1}}, \bar{K}_{1}\right), \bar{K}_{1}\right)+f_{2}\left(L_{2}^{d}\left(w, \bar{K}_{2}\right), \bar{K}_{2}\right)\right] & =\left[1-A\left(L_{A}\right)\right] w
\end{aligned}
$$

where $L_{1}^{d}$ and $L_{2}^{d}$ are the demand functions of labor and $f_{1}$ and $f_{2}$ are the production functions in each productive sector.

Totally differentiating the equilibrium conditions with respect to $p_{1}$ and solving (and using the fact that $\frac{d f_{1}}{d L_{1}}=\frac{w}{p_{1}}$ and $\left.\frac{d f_{2}}{d L_{2}}=w\right)$ we find that:

$$
\frac{d L_{A}}{d p_{1}}=\frac{A\left(L_{A}\right)\left[\frac{1}{p_{1}^{2}} \frac{d L_{1}^{d}}{d\left(\frac{w}{p_{1}}\right)} *\left(p_{1} f_{1}+f_{2}\right)-f_{1} *\left(\frac{1}{p_{1}} \frac{d L_{1}^{d}}{d\left(\frac{w}{p_{1}}\right)}+\frac{d L_{2}^{d}}{d w}\right)\right]}{\left[A^{\prime} \times\left(Y_{K}+w \bar{L}\right)-w(1-A)\right]\left(\frac{1}{p_{1}} \frac{d L_{1}^{d}}{d\left(\frac{w}{p_{1}}\right)}+\frac{d L_{2}^{d}}{d w}\right)-A \times\left[\frac{d f_{1}}{d L_{1}} \frac{d L_{1}^{d}}{d\left(\frac{w}{p_{1}}\right)}+\frac{d f_{2}}{d L_{2}} \frac{d L_{2}^{d}}{d w}\right]+(1-A) L_{A}}
$$

where $Y_{K}$ denotes the income of capital.

Note the denominator is positive if and only if:

$$
A^{\prime}\left(L_{A}\right)\left(Y_{K}+w \bar{L}\right)-w \leq \frac{A\left(L_{A}\right)\left[\frac{d f_{1}}{d L_{1}} \frac{d L_{1}^{d}}{d\left(\frac{w}{p_{1}}\right)}+\frac{d f_{2}}{d L_{2}} \frac{d L_{2}^{d}}{d w}\right]-\left(1-A\left(L_{A}\right)\right) L_{A}}{\left(\frac{1}{p_{1}} \frac{d L_{1}^{d}}{d\left(\frac{w}{p_{1}}\right)}+\frac{d L_{2}^{d}}{d w}\right)}+w A
$$


given that $\frac{d L_{1}^{d}}{d\left(\frac{w}{p_{1}}\right)}$ and $\frac{d L_{2}^{d}}{d w}$ are negative. The left hand side of equation (13) is negative by the concavity of $A$ and the equilibrium condition of the appropriation sector. The right hand side of equation (13) can be shown to be positive using the fact that $\frac{d f_{1}}{d L_{1}}=\frac{w}{p_{1}}$ and $\frac{d f_{2}}{d L_{2}}=w$. Hence, the denominator is positive. Using again the fact that $\frac{d f_{1}}{d L_{1}}=\frac{w}{p_{1}}$ and $\frac{d f_{2}}{d L_{2}}=w$ it can be shown that the numerator is positive if and only if the condition of the proposition holds.

Proof of Proposition 11. Let $q_{1}=K_{1}^{\alpha} L_{1}^{1-\alpha}$ and $q_{2}=K_{2}^{\beta} L_{2}^{1-\beta}$ be the production functions in the productive sectors. Then the equilibrium conditions in (10) and (11) become:

$$
\begin{gathered}
(1-\alpha)^{\frac{1}{\alpha}}\left(\frac{p_{1}}{w}\right)^{\frac{1}{\alpha}} \bar{K}_{1}+\alpha^{\frac{1}{1-\alpha}}\left(\frac{1}{w}\right)^{\frac{1}{1-\alpha}} \bar{K}_{2}+L_{A}=\bar{L} \\
A\left(L_{A}\right)\left((1-\alpha)^{\frac{1-\alpha}{\alpha}}\left(\frac{p_{1}}{w}\right)^{\frac{1}{\alpha}} \bar{K}_{1}+(1-\beta)^{\frac{1-\beta}{\beta}}\left(\frac{1}{w}\right)^{\frac{1}{\beta}} \bar{K}_{2}\right)=\left(1-A\left(L_{A}\right)\right) w L_{A}
\end{gathered}
$$

From the equilibrium conditions it follows that multiplying $p_{1}$ for a factor $\Delta$ will have the same effect on the equilibrium value of the endogenous variables than multiplying $K_{1}$ for a factor $\Delta^{\frac{1}{\alpha}}$. Therefore, noting that in this case $\sigma_{1}=\sigma_{2}=-1, \theta_{L 1}=\alpha$ and $\theta_{L 2}=\beta$, the result follows from Proposition 10.

\section{The case when appropriation employs labor and capital}

We now show that the results of the paper also hold when both capital and labor are used in the appropriation sector under the condition that this sector is labor intensive relative to the whole economy. Consider the economy from section 2 with the only difference that now the amount of appropriation is $A\left(L_{A}, K_{A}\right)\left[p_{1} q_{1}+q_{2}\right]$. We assume that the appropriation sector combines labor and capital in amounts that minimize the cost of a given amount of appropriation and that, as before, $A\left(L_{A}, K_{A}\right)$ presents decreasing returns to scale. In equilibrium, the returns from appropriation must equal the total value of the factors used in the sector:

$$
A\left(L_{A}, K_{A}\right)\left[r\left(\bar{K}-K_{A}\right)+w\left(\bar{L}-L_{A}\right)\right]=\left[1-A\left(L_{A}, K_{A}\right)\right] w L_{A}+\left[1-A\left(L_{A}, K_{A}\right)\right] r K_{A} .
$$

We study next how changes in prices affect the level of activity of the appropriation sector.

Proposition 12 An increase in the price of the capital intensive output results in an increase in the level of activity of the appropriation sector $\left(\frac{d A}{d p_{1}}>0\right)$ if and only if the appropriation sector is labor intensive relative to the economy $\left(\frac{L_{A}}{K_{A}}>\frac{\bar{L}}{\bar{K}}\right)$.

Proof. The equilibrium condition for the appropriation sector can be written as $A=$ $\frac{\frac{r}{w} K_{A}\left(A, \frac{r}{w}\right)+L_{A}\left(A, \frac{r}{w}\right)}{\frac{r}{w} \bar{K}+\bar{L}}$, where $A$ is the level of appropriation and $K_{A}\left(A, \frac{r}{w}\right)$ and $L_{A}\left(A, \frac{r}{w}\right)$ are the demands of capital and labor of the appropriation sector given the level of appropriation and the ratio of factor prices. 
Remember that by the Stolper-Samuelson theorem (Lemma 1) $\frac{d \frac{r}{w}}{d p_{1}}$ is positive and we can focus on the sign of $\frac{d A}{d \frac{r}{w}}$. Differentiating the equilibrium condition with respect to $\frac{r}{w}$ we obtain: $\frac{d A}{d \frac{r}{w}}=\frac{\frac{r}{w} \frac{d K_{A}}{d \frac{r}{w}}+\frac{d L_{A}}{d \frac{r}{w}}+K_{A}-\left(\frac{\frac{r}{w} K_{A}+L_{A}}{\frac{r}{w} \bar{K}+\bar{L}}\right) \bar{K}}{\frac{r}{w} \bar{K}+\bar{L}-\left(\frac{r}{w} \frac{d K_{A}}{d A}+\frac{d L_{A}}{d A}\right)}$. Using the Envelope theorem $\left(\frac{r}{w} \frac{d K_{A}}{d \frac{r}{w}}+\frac{d L_{A}}{d \frac{r}{w}}=0\right)$

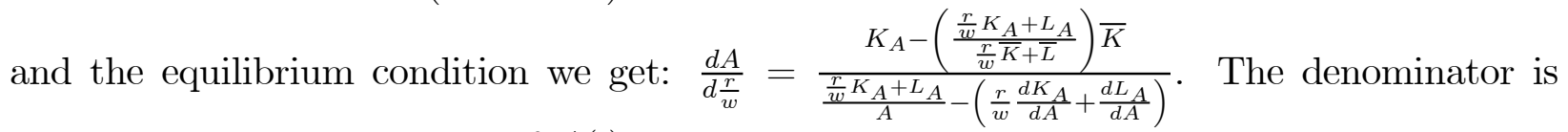
negative given that, because of $A($.$) having decreasing returns to scale, the average cost is$ lower than the marginal cost. The numerator is negative if and only if $\frac{L_{A}}{K_{A}}>\frac{\bar{L}}{\bar{K}}$ and the result follows.

As in Section 4, changes in technology can be studied in a way analogous to the one just used to study price changes. Another source of variation in the level of conflict is changes in endowments. As discussed in section 4.2, studying the effect of changes in the total endowment of resources that may participate in the appropriation sector requires that we redefine the appropriation technology so as to consider both the amount of the resource in the appropriation sector and that in the rest of the economy. Otherwise, as the total amount of the resource grows, the appropriation sector would grow as well up to the point in which it takes over the whole economy. We then define appropriation as a function of the share of each resource in the appropriation technology, i.e. $A\left(k_{A}, l_{A}\right)$ where $k_{A}=\frac{K_{A}}{\bar{K}}$ and $l_{A}=\frac{L_{A}}{\bar{L}}$. It is interesting to note that the impact of an increase in the total endowment of one factor depends on the factor intensity of the appropriation sector.

Proposition 13 An increase in the amount of capital results in an increase in conflict $\left(\frac{d A}{d \bar{K}}>0\right)$ and an increase in the amount of labor results in a decrease in conflict $\left(\frac{d A}{d \bar{L}}<0\right)$ if and only if the appropriation sector is labor intensive relative to the economy $\left(\frac{L_{A}}{K_{A}}>\frac{\bar{L}}{\bar{K}}\right)$.

Proof. The equilibrium condition for the appropriation sector can be written as $A=$ $\frac{\frac{r}{w} k_{A}\left(A, \frac{r}{w}, \bar{K}, \bar{L}\right) \bar{K}+l_{A}\left(A, \frac{r}{w}, \bar{K}, \bar{L}\right) \bar{L}}{\frac{r}{w} \bar{K}+\bar{L}}$, where $A$ is the level of appropriation and $k_{A}\left(A, \frac{r}{w}, \bar{K}, \bar{L}\right)$ and $l_{A}\left(A, \frac{r}{w}, \bar{K}, \bar{L}\right)$ are the demands of capital and labor of the appropriation sector given the level of appropriation, the price of inputs and total factor endowments. Differentiating this condition with respect to $\bar{K}$ we obtain: $\frac{d A}{d \bar{K}}=\frac{\frac{r}{w} \frac{d k_{A}}{d \bar{K}}+\frac{d l_{A}}{d \bar{K}}+\frac{r}{w} k_{A}-\frac{r}{w}\left(\frac{\frac{r}{w} k_{A} \bar{K}+l_{A} \bar{L}}{\frac{r}{w}+\bar{L}}\right)}{\frac{r}{w} \bar{K}+\bar{L}-\left(\frac{r}{w} \frac{d K_{A}}{d A}+\frac{d L_{A}}{d A}\right)}$. By the Envelope theorem $\left(\frac{r}{w} \frac{d k_{A}}{d \bar{K}}+\frac{d l_{A}}{d \bar{K}}=0\right)$ and the equilibrium condition for appropriation we have:

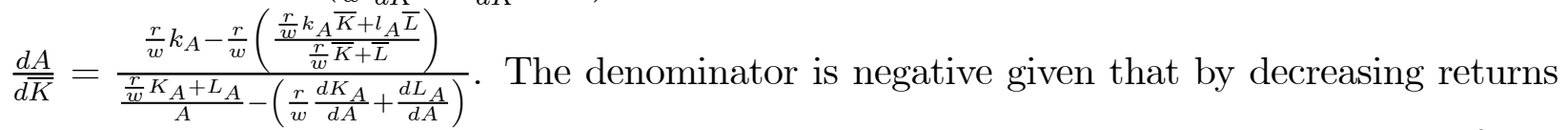
to scale the average cost is lower than the marginal cost. The numerator is negative if and only if $\frac{L_{A}}{K_{A}}>\frac{\bar{L}}{\bar{K}}$ and the result for changes in $\bar{K}$ follows. By symmetry we have that $\frac{d A}{d \bar{L}}<0$ if and only if $\frac{L_{A}}{K_{A}}>\frac{\bar{L}}{\bar{K}}$. 
The extension of the results in section 5 to the case in which both capital and labor are used in appropriation follow from the previous two propositions. 


\section{References}

Acemoglu, D., S. Johnson, and J. Robinson (2001). "The Colonial Origins of Comparative Development: An Empirical Investigation," American Economic Review 91(5), 1369401.

Acemoglu, D. and J. Robinson (2001a). "Inefficient Redistribution," American Political Science Review 95(3), 649-61.

Acemoglu, D. and J. Robinson (2001b). "A Theory of Political Transitions," American Economic Review 91(4), 938-63.

Ades, A. and R. Di Tella (1999). "Rents, Competition and Corruption," American Economic Review 89(4), 982-94.

Bhagwati, J. and T.N. Srinivasan (1980). "Revenue Seeking: A Generalization of the Theory of Tariffs," Journal of Political Economy 88(6), 1069-87.

Becker, G. (1968). "Crime and Punishment: An Economic Approach," Journal of Political Economy 76(2), 169-217.

Becker, G. (1983). "A Theory of Competition Among Pressure Groups for Political Influence," Quarterly Journal of Economics 98(3), 371-400.

Coate, S. and S. Morris (1995). "On the Form of Transfers to Special Interests," Journal of Political Economy 103(6), 1210-35.

Collier P. and A. Hoeffler (1998). "On Economic Causes of Civil War," Oxford Economic Papers, 50, 563-73.

Elbadawi, I. and N. Sambanis (2002). "How Much Civil War Will We See? Explaining the Prevalence of Civil War," Journal of Conflict Resolution, 46(3), 307-34.

Ehrlich, I. (1973). "Participation in Illegitimate Activities: A Theoretical and Empirical Investigation," Journal of Political Economy 81(3), 521-65.

Fajnzylber, P., D. Lederman and N. Loayza (2002). "Inequality and Violent Crime," Journal of Law and Economics 45(1), 1-40.

Fearon, J. and D. Laitin (2003). "Ethnicity, Insurgency, and Civil War," American Political Science Review, 97(1), 75-90. 
Garfinkel, M.R. (1990). "Arming as a Strategic Investment in a Cooperative Equilibrium," American Economic Review, 80(1), 50-68.

Gould, E.D., Weinberg, B.A. and D.B. Mustard (2002). "Crime Rates and Local Labor Market Opportunities in the United States: 1979-1997," Review of Economics and Statistics, 84(1), 45-61.

Grogger, J. (1998). "Market Wages and Youth Crime," Journal of Labor Economics, 16(4), 756-91.

Grossman, H. (1991), "A General Equilibrium Model of Insurrections," American Economic Review 81(4), 912-21.

Grossman, H.I. and M. Kim (1995). "Swords or Plowshares? A Theory of the Security of Claims to Property," Journal of Political Economy, 103(6), 1275-88.

Hirshleifer, J. (1995). "Anarchy and Its Breakdown," Journal of Political Economy, 103(1), 26-52.

Jones, R.W. (1965). "The Structure of Simple General Equilibrium Models," Journal of Political Economy 73(6), 557-72.

Krueger, A. (1974). "The Political Economy of the Rent Seeking Society," American Economic Review 64(3), 291-303.

MacCulloch, R. (2001). "What Makes a Revolution?," working paper, STICERD.

Meller, P. (2003). "A Developing Country View of Tariff and Trade Barriers," paper presented to OECD Forum on Trade "Moving forward on market access in the Doha development agenda".

Miguel, E., Satyanath, S. and E. Sergenti (2004). "Economic Shocks and Civil Conflict: An Instrumental Variables Approach," forthcoming Journal of Political Economy.

Mussa, M. (1974). "Tariffs and the Distribution of Income: The Importance of Factor Specificity, Substitutability, and the Intensity in the Short and Long Run," Journal of Political Economy 82(6), 1191-1203.

Peltzman, S. (1976). "Toward a More General Theory of Regulation," Journal of Law and Economics 19, 211-48.

Powell, R. (2004). "The Inefficient Use of Power: Costly Conflict With Complete Information," American Political Science Review 98(2), 231-41. 
Prebisch, R. (1959). "Commercial Policy in the Underdeveloped Countries," American Economic Review 49(2), 251-73.

Ross, M. (2003). "The Natural Resource Curse: How Wealth Can Make You Poor," in Collier, P. and I. Bannon (eds.) Natural Resources and Violent Conflict. The World Bank.

Rybczynski, T. (1955). "Factor Endowment and Relative Commodity Prices," Economica $22,336-41$.

Skaperdas, S. (1992). "Cooperation, Conflict, and Power in the Absence of Property Rights," American Economic Review 82(4), 720-39.

Stigler, G. (1971). "The Theory of Economic Regulation," Bell Journal of Economics and Management Science 2, 3-21.

Stolper, W. and P. Samuelson (1941). "Protection and Real Wages," Review of Economic Studies 9(1), 58-73. 